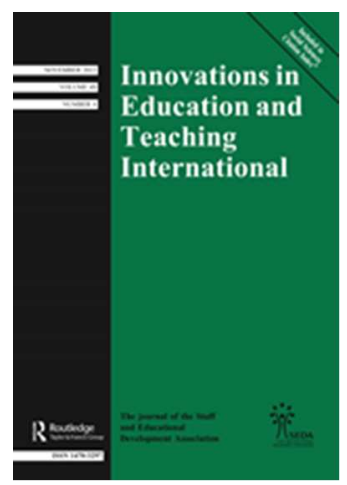

\title{
Use of animation in engaging teachers and students in assessment in Hong Kong higher education
}

\begin{tabular}{|r|l|}
\hline Journal: & Innovations in Education and Teaching International \\
\hline Manuscript ID: & RIIE-2013-0007.R1 \\
\hline Manuscript Type: & Original Article \\
\hline Areas of Interest: Keywords: & $\begin{array}{l}\text { assessment, animation, youtube, learning technologies, technology } \\
\text { enhanced learning }\end{array}$ \\
\hline \multicolumn{2}{|l}{} \\
\hline
\end{tabular}

SCHOLARONE

Manuscripts 


\title{
Use of animation in engaging teachers and students in assessment in Hong Kong higher education
}

\begin{abstract}
Animations have long been perceived as an effective tool in teaching and learning. While students' reception towards animations has often been studied, there is also literature covering how teachers perceive and incorporate animations into their classes. At a research intensive university in Hong Kong, animations on the topic of university assessment policy, such as rubrics and grade descriptors, have been produced so that teachers can understand the latest policy quickly without attending lengthy workshops. It was found that a striking $95 \%$ of teachers reported gaining better understanding of assessment rubrics after watching the animation. This paper will present the findings from a small study on how teachers perceive the use of animations for their own professional development, and how they perceive the incorporation of animations into their own disciplines to engage students. Despite positive attitude towards the use of animation for teaching and learning, academics expressed practical and technical concerns.
\end{abstract}

Keywords: assessment; animation; youtube; learning technologies; technology enhanced learning 
At a research intensive university in Hong Kong, an assessment policy has been approved at the institutional level to provide quality assurance and standards for both teachers and students (Chan, 2012a). With the implementation of such an important teaching and learning policy, it is crucial to ensure that teachers can fully comprehend the meaning of each approved recommendation so they can put the policy into practice. This requires them to attend teaching and learning professional development workshops and seminars which they are often too busy to do so. To quickly engage teachers and allow them to effectively grasp the meaning of some of these practices, cartoon animations were developed to illustrate the main themes of the assessment policy.

With the advanced development in multimedia technology over the last decade, animation has been increasingly employed for teaching and learning. This is evidenced by the escalating number of users on 'youtube' or 'teachertube' (Snelson \& Elison-Bowers, 2009). In fact, animation is a useful and effective teaching tool. It can be humorous and engaging, short and yet concise, allowing teachers to demonstrate an idea in minimum time. Previous studies showed that animations can effectively illustrate abstract and complex concepts (Barak, Ashkar, \& Dori, 2011; Ong \& Mannan, 2004). It can deliver knowledge in both 2D and 3D visual and audio, and allows users to experience the simulation of a realworld scenario which may be difficult to explain without illustrations or actual practices. Furthermore, the use of animation can help students to develop their critical thinking, problem solving skills and their engagement to the subject content (Keogh, 1999; Mayer \& Moreno, 2002).

With animations on the assessment policy developed, a few brief pilot studies were carried out to demonstrate the effectiveness of these animations towards the understanding of assessment concepts during the teaching and learning academic professional 
development workshops at the university. Using a classroom response system "clickers", two multiple choice questions on teachers' understanding of the assessment concept were asked before and after they watched an animation on assessment rubrics (Chan, Tam \& $\mathrm{Li}$, 2011). The value-added benefits of the assessment rubrics can often be difficult to grasp by teachers as they are not used to showing clarity on their marking schemes; such transparency and indeed, added workload can be quite a turnoff. A sharp contrast was observed such that around $95 \%$ of the teachers who attended the workshop reported better understanding of the assessment rubrics after watching the animation. This shows that animation can be an effective teaching tool to explain some difficult theoretical framework in an interesting and entertaining way.

While students' reception and student learning towards animations have often been studied, and there is also literature covering how teachers perceive and incorporate animations into their classes, teachers' reception towards animations for academic professional development has not been fully documented. Thus, the present small study aims to contribute to the literature on how teachers perceive the use of animations for their own learning towards the understanding of assessment concepts and if they may be as receptive as their students to digital media, as well as how teachers perceive for-using animations to engage students in their own disciplines.

\section{Literature review}

\section{Literature Review}

With the advanced development in technology over the last decade, multimedia has been increasingly perceived as an effective tool in teaching and learning. Students nowadays are growing up with multimedia technology, such as video games, 3D animations, online 
videos and colorful graphics. Since technological visual abilities have been sharpened, students have become primarily visual learners (Roberto, 2010). Students in this generation are often known as the "digital generation". One of the characteristics of digital learners is that they prefer receiving information from multiple multimedia sources and processing pictures, sounds and videos before text (Jukes, McCain, \& Crockett, 2010). In contrast, traditional teaching and learning resources that often deliver knowledge through static images and texts might not be as appealing and as effective to accommodate the learning enthusiasm of these digital learners. Thus, multimedia technology offers teachers an alternative means to facilitate teaching and learning to the digital generation. Studies have shown that integrating these digital resources with teaching can stimulate the learning interests and motivation of students (Burke, Snyder, \& Rager, 2009; Duffy, 2008).

Among the various types of multimedia resources, video is most commonly used as a pedagogical material. Cartoon animations, YouTube, virtual simulations, and other digital devices and software that used to broadcast these videos, such as smart phones and tablet computers are all toys of the digital generation.

\section{Animation}

Animation such as cartoons or 3D virtual reality simulations is usually defined as computer generated moving imageries that have integrated various components of conventional media, such as video, graphics, audio in 2D or 3D illustrations (Szabo \& Poohkay, 1996). Many scholars have researched and concluded that the usage of animations in teaching is beneficial to student learning. In various studies, improvements can be seen in areas including abstract thinking, communication skills and problem-solving skills, thinking skills and learning engagement. It was also shown that animation can assist students to 
achieve the expected learning outcomes. Animation was found to be a learning tool with significant positive effects on the learning process (Fralinger \& Owens, 2009).

A review of literature shows that one of the most agreed benefits of animations for student learning is that animations enable the visualization of abstract concepts, particularly in science and mathematics (Lipeikiene \& Lipeika, 2006; Yang, Andre, \& Greenbowe, 2003). Scholars, such as Ong \& Mannan (2004) and Dalacosta et al. (2009), argue that creating visualizing abstract concepts can be a challenging cognitive process for science learners. In the past, students might find it hard to comprehend some abstract and complicated concepts in their minds from texts and static pictures. However, the use of animation, such as 3D virtual reality and real-world simulation, it has provided visual cues for students to enhance their cognitive processing. In fact, animation was found to be able to reinforce the process of visualization as an effective cognitive strategy to enhance conceptual understanding (Marbach-Ad, Rotbain, \& Stavy, 2008; Williamson \& Abraham, 1995). Mayer \& Moreno (2002) further elaborated that animations are effective as they are designed in ways that promote the human cognitive process - to have corresponding pictorial and verbal (narrations) representations in the human memory at the same time. Barak and colleagues (2011) echoed such thought, stating that animations allow students to engage in three learning styles simultaneously - visual, auditory and kinesthetic - which increases their knowledge comprehension.

Another widely perceived benefit of animation is that it increases students' motivation to learn. It is a useful tool which increases attention and academic interests of students towards learning (Dalacosta, et al., 2009; Wang \& Reeves, 2006). Barak and colleagues (2011) found that students who use animations to learn have higher motivation for categories of self-efficacy, enjoyment, connection to daily life and importance to their 
future compared to those who do not. Other studies indicated that animation can be an icebreaker to initiate class discussion and facilitate interesting, interactive and even entertaining lecture without putting in a huge amount of work and time spent on teaching preparation (Fralinger \& Owens, 2009).

The benefits of animation have been widely perceived to be positive. However, whether the use of animations can contribute to teaching and learning is determined by how it is used. To incorporate animations into teaching and learning, teachers need to be aware of the practical, technical and pedagogical aspects of animations. Practical aspects refer to the usability of animation as a means in the educational context. This may include the choice of animation, length of the class and classroom environment. Technical aspects can be the making of animations, computing competency of teachers, technical support and resources. Pedagogical aspects may cover the academic value of the content, and the alignment of animations with the expected learning outcomes. The amount and timing of add-ons such as narrations and on-screen text should be appropriately matched to the animation pictures to avoid overloading the audiences.

Teachers should not perceive animation as a replacement for traditional teaching methods, but as a means of supporting and enhancing learning within the traditional classroom environment (Tan \& Pearce,2011). For example, static form of vague or unclear questions could be misread or misinterpreted in a way that could be much easily clarified by animations (Dancy \& Beichner,2006). Animations can effectively reinforce traditional teaching and learning to achieve learning objectives.

In order to develop a deeper understanding in the pedagogy of assessment, cartoon animations were developed to inform, interpret and unveil the more mythical concepts of assessment for the academics at a research-intensive university in Hong Kong. Five 


\section{Methodology}

The survey aimed to gauge teachers' perception towards: 1) the benefits of applying animations in teaching and learning, 2) whether using animations can align with learning outcomes and 3) its effectiveness in teaching and learning. The survey was divided into two sections. In the first section, participants were asked to express their opinions on the assessment animations in terms of its ability to achieve learning outcomes. The section also 
collected data on teachers' attitudes towards the perceived benefits of animations. The second section aimed to gauge teachers' perception in using animations in their own courses. Teachers were asked about what constitutes good animation design, the usefulness of animations and ways to improve animations in pedagogical aspects. The survey consisted of five 'Yes/No' questions, four open-ended questions, and six questions measured on a 5-point Likert Scale.

The survey was piloted with five teachers who attended the teaching and learning workshops and some wordings were consequently revised in the survey. The survey was posted on an open source online survey system (Lime Survey). An email invitation explaining the nature and purpose of the study was sent to teaching staff and research members who participated in the three different teaching and learning workshops at university. The email attached links to access the online survey and the cartoon animations on assessment concepts. For those who preferred not to complete the survey online, an electronic copy of the survey was also attached in the email. Participants had two weeks to complete the survey.

\section{Results}

A total of 51 staff members across 19 different departments responded to the survey. A summary of the result of teachers' responses to items on the assessment animations is provided in Table 1 below.

[Insert Table 1 here]

Most of the participants indicated that the cartoon animations achieved their objectives and learning outcomes of demonstrating the assessment concepts $(68.6 \%$ 'Agree' and $13.7 \%$ 'Strongly Agree'). They also reported that their colleagues would 
benefit from the animations on teaching and learning (58.8\% 'Agree' and 7.8\% 'Strongly

Agree'). These participants suggested that watching animations was an entertaining and practical way to learn about assessment concepts particularly when compared to lectures or written pedagogical methods. Selected quotes from respondents included that

"Understand the teaching \& learning methods in an interesting ways. Sometimes a little bit boring just listening to lecture."

"They communicate important messages in a clear, easy and enjoyable way."

"It is a much more enjoyable way to learn by looking at animations than reading papers."

In the open-ended response, words and descriptions such as "fun", "lively", "enjoyable" were repeatedly used by respondents to describe the animations.

[Insert Table 2 here]

Table 2 above presents teachers' perception of a good animation. Many of them strongly agree that a good animation needs to be able to achieve the following: explain and illustrate abstract and complex concepts more effectively (34.9\% 'Agree', $53.5 \%$ 'Strongly Agree'), deliver teaching content in a more interesting and entertaining way (30.2\% 'Agree', $60.5 \%$ 'Strongly Agree'). Participants also agree that good animations should be short (51.9\% 'Agree', 11.1\% 'Strongly Agree'), precise (61.8\% 'Agree', 35.3\% 'Strongly Agree'), humorous (57.6\% 'Agree', 30.3\% 'Strongly Agree') and able to demonstrate practical skills to students with real world scenarios (57.6\% 'Agree' and 33.3\% 'Strongly Agree').

Some participants responded that their most important concerns when using animations for teaching are: 1) whether animations can facilitate the interaction among students; 2) whether complex ideas can be effectively explained by animations; 3 ) whether 
animations can motivate students to be interested in the subject. Some of the qualitative comments indicated that teachers recognized the benefits of animations:

"They [animations] can serve, for instance, as a nice ice-breaking activity in briefing students on the assessment of the course."

"I would like to use it to provide variety and humour into teaching."

"I think it attracts the attention of the audiences. It is more interesting to learn by visual stimulation."

Participants' reported use of animation is presented in Table 3 below. More than half of the participants (82.9\%) never used animations for teaching because they did not have the resources (e.g. time) and technical knowledge to produce their own animations. Some teachers also commented that it is hard to find animations explaining specific complex concepts at a professional level for some disciplines, such as science. Therefore, some of them suggested that there should be more support on animation or video production. When asked whether they will consider using animations in their courses in future, only around one-fifth (33.3\%) of the total respondents answered 'yes' while the majority (61.1\%) answered 'maybe'. The open-ended comments indicated that teachers are willing to try if such resources are readily at hand.

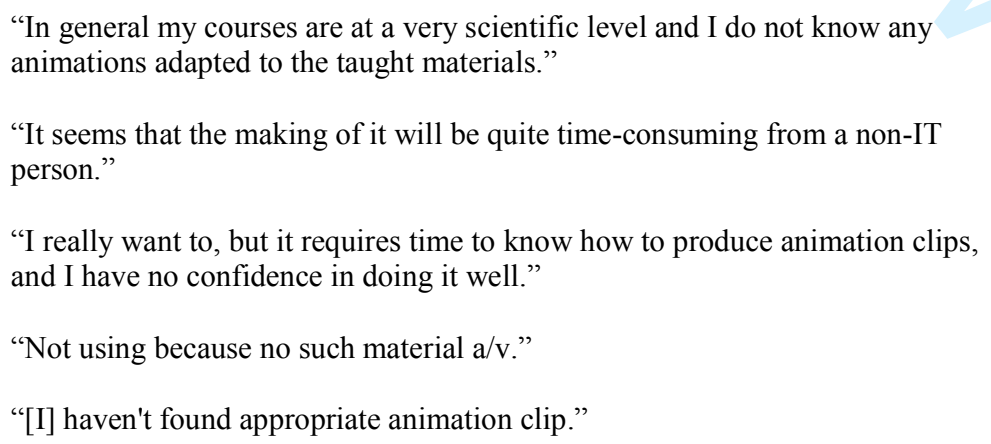


Finally, participants were asked to provide any suggestions for improvements of the teaching and learning animations. Some participants suggested improving the interactivity of the animations to stimulate class discussions, such as segmenting animations into smaller sessions so that teachers can ask questions during the process and students can express their opinions at different intervals. Other recommendations were on issues such as technical improvements (quality, dubbing, English language, length, graphics) and production/marketing strategies for the animations. One participant was interested to find out more about using animation as in-class pedagogy to improve student engagement.

\section{Discussion and conclusions}

Both quantitative and qualitative results indicated that academics who participated in our study perceive animations to be effective in introducing assessment concepts and assessment policy of the university. The results showed that the teachers believe that the animations have achieved their objectives and learning outcomes, and benefited their colleagues on teaching and learning. Some teachers agreed that the animations can deliver knowledge in an entertaining and practical way. Our findings thus suggest that animations can be used effectively to introduce assessment concepts to academics at the teaching and learning workshops.

Our study also pointed out teachers' perceived characteristics of -good animation in teaching and learning. The results suggested two criteria which academics consider as extremely important for animation to be effective. First, teachers perceive a good animation as one which must be able to explain and illustrate abstract and complex concepts effectively. 
Second, teachers perceive a good animation as one which is able to deliver teaching content in a more interesting and entertaining way. Some teachers in our study believe that introducing ideas, particularly complex and abstract concepts and theories, to students through the use of fun and attractive animation will enhance their attention and motivation towards the subject. Their belief is supported by findings from previous studies showing that animations effectively increase attention, interests and motivation of students towards learning, and eventually enhance attitudes, productivity, creativity, interaction and divergent thinking. With the support of audio effect and visual cues, animations enable academics to illustrate the teaching content in a lively and even humorous way. This reinforces the learning process by attracting students' interests and attention, and even directs them to the expected learning outcomes. Animation is also perceived as an interesting tool which makes the teaching approach and classroom environment more engaging and entertaining as a whole. In contrast, traditional teaching tools, such as transparencies and static graphics, are often considered as passive forms of learning and fail to sustain interests for a longer time. Therefore, the use of animation has advantage in delivering knowledge in a more interesting and enjoyable way particularly among the digital generation.

Generally, the pedagogical values of animations are positively recognized to be effective and significant. However, participants expressed concerns on the practical and technical issues in incorporating animations in their teaching. In fact, such issues play a significant role in promoting the use of animations in the educational contexts. If teachers do not have easy access to resources and technical support to develop animations, they would not apply it to their teaching practice. This is very true as mentioned before; the cost of our animation development was resource intensive - it required technical experts and 
good storyboard combined with pedagogical values. Technology can be used to facilitate learning process but it can also be an expensive waste of time if it is not appropriately instructed and used. Some academics might be novices at using animation and videos for their teaching. They may need guidance and support to prepare the animations. Therefore, usage feasibility and support significantly determines whether teachers are able to utilize animations in their teaching.

While the findings of the study demonstrated that most participants regard animation as a useful tool for teaching and learning, they also indicated that more than half of the participants never used animations for teaching. In fact, the proportion of participants who actually utilizes animations in their teaching is much lower than the proportion of participants who regards animations as beneficial to teaching and learning in this study. These contradictive findings could be explained by the qualitative results. The results revealed that time and resources are the main reasons which discourage teachers from using animation in their teaching. This might imply that even though animations are perceived to contribute to their teaching, practical and technical issues could prevent them from applying it to practice. Therefore, if more extensive animation usage is to be promoted, technical support and resources should be offered to teaching staff to tackle their workload concerns. One of the suggestions from the teaching and learning centre of the University of Hong Kong was to pilot the production of animations, videos or lecture capture teaching materials for faculties to use in their teaching, if this takes off, a multimedia central support centre may be setup to develop and to provide resources. This will reduce individual costs, provide a central support and community of practices for faculties. Lecture capture videos or Massive Open Online Courses (MOOCS) are becoming increasingly popular in higher education around the world as a teaching and learning tool for teachers. However, the 
author likes to point out that at this research intensive university in Hong Kong, this has not yet been the case. In fact, it was noted at several teaching and learning workshops, teachers' perceptions towards the idea of lecture capture were rather negative, they indicated that they would feel uncomfortable to share their materials and lectures with the public or even with their own students and being videoed. Panopto - a lecture-capture software has been installed into $30 \%$ of the classrooms at the university, this is currently being piloted and pedagogical benefits of using the software are being introduced to teachers. The traditional mentality of teachers would require time to adapt.

While the findings on incorporating animations in teaching and learning were largely positive, a few negative opinions were noted. Apart from technical issues, such as clarity of dubbing and duration length, a few academics mentioned that animation is not educative because it may trivialize the teaching content. In fact, whether the use of animation can direct students to a deeper level of knowledge or trivialize the teaching content is really determined by how it is utilized within the education context. Previous research pointed out that the purpose of using animation needs to be 'selectively' and 'critically' applied within the context, such as subject discipline, class size and resource availability. This is proposed as an important principle to promote on the use of animations in teaching and learning.

The primary purpose of the current study was to examine teachers' perceptions towards animations in engaging teaching and learning. The survey findings showed that academics perceive animations as an effective means of introducing assessment concepts and policy which will help enhance their professional knowledge and skills, suggesting that animation can be used as a powerful tool in teaching and learning. Apart from the use of 
animation for professional development, academics also believe that animation can be effectively used to engage students in their learning, especially when they are carefully designed to present information in an interesting manner and to explain abstract and complex concepts effectively. It was believed that the implementation of animation might create a relaxing and entertaining learning environment in which students are more comfortable and motivated to engage in class. Our animations did not include any interactive two-way feedbacks or inputs from the participants. This can easily be implemented and allow more teacher-participants and participant-participant interactions, to further engage them with learning.

In conclusion, the current study deepened the understanding of the pedagogical and practical aspects of animation in teaching and learning. Furthermore, usage feasibility and support were found to be significant in facilitating teachers in utilizing animations in teaching and learning. Further research should be carried out to look into the types of resources and practical support for teachers to incorporate animations into teaching and learning effectively and appropriately. The author has recently created a youtube channel "Cecilia KY Chan Education Channel" to broadcast all the animations created, these animations have been disseminated among the academic community worldwide and have received very positive feedback. She will continue to develop, create and share educational resources using this channel.

\section{References}

Barak, M., Ashkar, T.,\& Dori, Y. J.(2011). Learning science via animated movies: Its effect on students' thinking and motivation. Computers \& Education,56(3),839-846.

Biggs, J. B.(1999). Teaching for quality learning at university: What the student does. Philadelphia, PA:Society for Research into Higher Education.

Boud, D.(1995). Enhancing learning through self assessment. London: Kogan Page. 
Burke, S. C., Snyder, S.,\& Rager, R. C.(2009).An assessment of faculty usage of YouTube as a teaching resource. The Internet Journal of Allied Health Sciences and Practice 7(1),1-8.

Chan, C. K. Y.(2012a). Assessment for community service types of experiential learning in the engineering discipline. European Journal of Engineering Education,37(1),2938.

Chan, C. K. Y.(2012b). Identifying and understanding the graduate attributes learning outcomes in a case study of community service experiential learning project. International Journal of Continuing Engineering Education and Life Long Learning,22(1),148-159.

Chan, C. K. Y., Tam, V. W.,\& Li, C. Y. V.(2011). A comparison of MCQ assessment delivery methods for student engagement and interaction used as an in-class formative assessment. International Journal of Electrical Engineering Education, 48(3),323-337.

Chan, C. K. Y.,\& Luk, L. Y. Y.(2013). Faculty perspectives on the "334" curriculum reform in Hong Kong: Pros and cons. International Education Studies 6(4),56-66.

Dalacosta, K., Kamariotaki-Paparrigopoulou,M.,Palyvos, J. A.,\& Spyrellis,N.(2009). Multimedia application with animated cartoons for teaching science in elementary education. Computers \& Education,52(4),741-748.

Dancy, M. H.,\& Beichner, R.(2006). Impact of animation on assessment of conceptual understanding in physics. Physical Review Special Topics-Physics Education Research,2(1).

Duffy, P.(2008). Engaging the YouTube Google-eyed generation: Strategies for using web 2.0 in teaching and learning. The Electronic Journal of e-Learning, 6(2), 119-130.

Fralinger, B., \& Owens, R.(2009). YouTube as a learning tool. Journal of College Teaching and Learning,6(8),15-28.

Jukes, I., McCain, T. D. E.,\& Crockett, L.(2010).Living on the future edge: Windows on tomorrow. Thousand Oaks, Calif::Corwin.

Keogh,B.(1999). Concept cartoons, teaching and learning in science: An evaluation. International Journal of Science Education,21(4),431-446.

Lipeikiene, J.,\& Lipeika, A.(2006). Animation tools of CAS for dynamic exploration of mathematics. Informatics in education, 5(1),87-96.

Marbach-Ad, G., Rotbain, Y.,\&Stavy, R.(2008). Using computer animation and illustration activities to improve high school students' achievement in molecular genetics. Journal of Research in Science Teaching,45(3),273-292.

Mayer, R. E.,\& Anderson, R. B.(1992). The instructive animation: Helping students build connections between words and pictures in multimedia learning. Journal of Educational Psychology,84(4),444-452.

Mayer, R. E.,\&Moreno, R.(2002). Animation as an aid to multimedia learning. Educational Psychology Review, 14(1),87-99.

Ong, S. K.,\& Mannan, M. A.(2004). Virtual reality simulations and animations in a webbased interactive manufacturing engineering module. Computers \& Education,43(4),361-382.

Roberto, J.(2010). Teaching \& learning with the iGeneration: Perspectives, strategies, and ideas.Lifelong Faith,45-53.

Snelson, C.,\& Elison-Bowers, P.(2009). Using YouTube videos to engage the affective domain in e-learning.In A. Méndez-Vilas, A. S. Martin, J. A. M. Gonzálezm \& J. M. 
Table 2. Teachers' responses to items on the criteria of a good animation

Table 1. Teachers' responses to items on the assessment animations

\begin{tabular}{llccccc}
\hline \multicolumn{1}{c}{$\begin{array}{c}\text { Items on the assessment } \\
\text { animations }\end{array}$} & $n \begin{array}{c}\text { Strongly } \\
\text { Disagree } \\
(\%)\end{array}$ & $\begin{array}{c}\text { Disagree } \\
(\%)\end{array}$ & $\begin{array}{c}\text { Neutral } \\
(\%)\end{array}$ & $\begin{array}{c}\text { Agree } \\
(\%)\end{array}$ & $\begin{array}{c}\text { Strongly } \\
\text { Agree } \\
(\%)\end{array}$ \\
\hline $\begin{array}{l}\text { 1. I enjoyed the animation. } \\
\text { 2. The animation achieved its } \\
\begin{array}{l}\text { Thjectives and learning outcomes. } \\
\text { The length of the animation is } \\
\text { appropriate. }\end{array}\end{array}$ & 51 & 5.9 & 5.9 & 5.9 & 56.9 & 25.5 \\
$\begin{array}{l}\text { My colleagues will benefit from } \\
\text { these animations on teaching and } \\
\text { learning. }\end{array}$ & 51 & 7.8 & 2.0 & 7.8 & 68.6 & 13.7 \\
\end{tabular}

González (Eds.), Research, reflections and innovations in integrating ICT in education (Vol. 3, pp. 1481-1485).Badajoz, Spain: FORMATEX.

Szabo, M.,\& Poohkay, B.(1996). An experimental study of animation, mathematics achievement, and attitude toward computer-assisted instruction. Journal of Research on Computing in Education,28(3),390-402.

Wang, S. K.,\& Reeves,T. C.(2006). The effects of a Web-based learning environment on student motivation in a high school earth science course. Educational Technology Research and Development,54(6),597-621.

Williamson, V. M.,\& Abraham, M. R.(1995). The effects of computer animation on the particulate mental models of college chemistry students. Journal of Research in Science Teaching,32(5),521-534.

Yang, E. M., Andre, T.,\& Greenbowe, T. J.(2003). Spatial ability and the impact of visualization/animation on learning electrochemistry. International Journal of Science Education, 25(3),329-349.

\begin{tabular}{|c|c|c|c|c|c|c|}
\hline $\begin{array}{l}\text { Items on the criteria of a good } \\
\text { animation }\end{array}$ & $n$ & $\begin{array}{l}\text { Strongly } \\
\text { Disagree } \\
(\%)\end{array}$ & Disagree & $\begin{array}{l}\text { Neutral } \\
(\%)\end{array}$ & $\begin{array}{l}\text { Agree } \\
(\%)\end{array}$ & $\begin{array}{l}\text { Strongly } \\
\text { Agree } \\
(\%)\end{array}$ \\
\hline A good animation must be... & & & & & & \\
\hline a) Short & 27 & 0 & 7.4 & 29.6 & 51.9 & 11.1 \\
\hline b) Precise & 34 & 0 & 0 & 2.9 & 61.8 & 35.3 \\
\hline c) Humorous & 33 & 0 & 0 & 12.1 & 57.6 & 30.3 \\
\hline $\begin{array}{l}\text { d) Able to deliver the Learning } \\
\text { Outcomes }\end{array}$ & 33 & 0 & 0 & 18.2 & 42.4 & 39.4 \\
\hline $\begin{array}{l}\text { e) Able to demonstrate some } \\
\text { practical skills to students with } \\
\text { real world scenarios }\end{array}$ & 33 & 0 & 6.1 & 3.0 & 57.6 & 33.3 \\
\hline
\end{tabular}


Table 3. Teachers' responses to items on the use of animation

\begin{tabular}{lcccc}
\hline $\begin{array}{l}\text { Items on the use of animation } \\
(n=51)\end{array}$ & $n$ & Yes & No & Maybe \\
\hline I have used animation in my own course. & 35 & 17.1 & 82.9 & 0 \\
I will use animation in my own course in the future. & 36 & 33.3 & 5.6 & 61.1
\end{tabular}

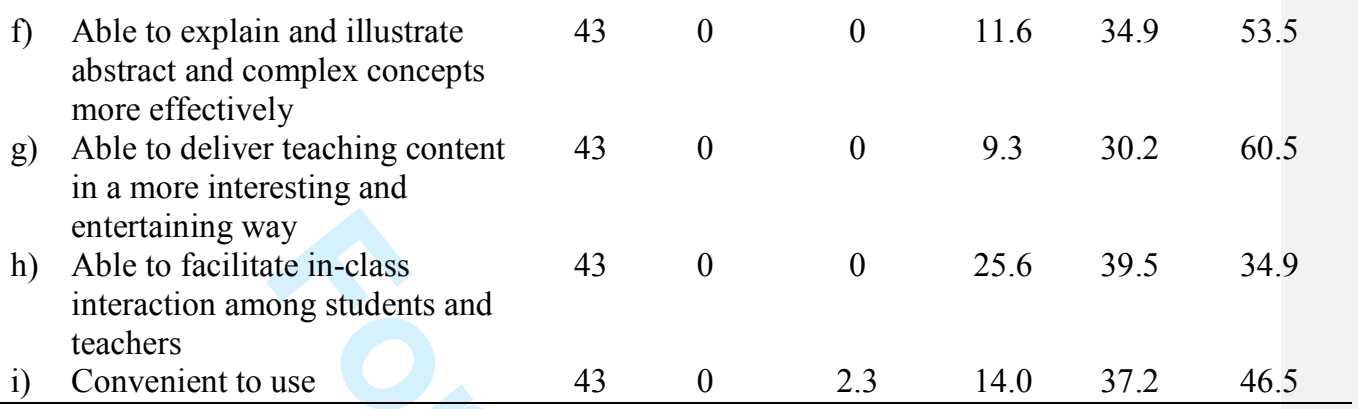

